\title{
Body shape variation in meiotic gynogenetic and triploid sea bass, Dicentrarchus labrax
}

\author{
Stefano Peruzzi ${ }^{1, a}$, Stine Wiborg-Dahle ${ }^{1,2}$ Pierrick Haffray $^{3}$, Béatrice Chatain ${ }^{4}$ and Raul Primicerio ${ }^{1}$ \\ 1 University of Troms $\varnothing$, Department of Arctic and Marine Biology, Faculty of Biosciences, Fisheries and Economics, 9037 Troms $\varnothing$, Norway \\ 2 SINTEF, Fisheries and Aquaculture AS, 7465 Trondheim, Norway \\ 3 Syndicat des Sélectionneurs Avicoles et Aquacoles Français (SYSAAF), Station INRA/SCRIBE, Campus de Beaulieu, 35042 Rennes, France \\ ${ }^{4}$ IFREMER, Laboratoire de Recherche Piscicole de Méditerranée, chemin de Maguelone, 34250 Palavas-les-Flots, France
}

Received 19 February 2010; Accepted 30 June 2010

\begin{abstract}
A method of geometric morphometrics was used to characterize body shape variation in meiotic gynogenetic and triploid sea bass in comparison with diploid controls. A total of 13 coordinate landmark data were recorded on the profile of 34-month-old control $(n=81)$, gynogenetic $(n=117)$ and triploid $(n=131)$ siblings generated from two females (A and B). Three main axes of morphometric variation were consistent, and these accounted for 60.8 and $57.6 \%$ of the total variability in females A and B, respectively. There were significant shape deviations of triploid and gynogenetic fish relative to the controls, and differences were particularly evident in the progeny of one female. Overall, triploids displayed a more slender shape than diploids, whereas gynogenetic fish were deeper bodied and had flexed caudal peduncles and cranial features. The results are discussed especially in relation to the characterization of triploid fish for commercial purposes.
\end{abstract}

Key words: Body shape variability / Morphometry / Geometry of Procrustes distance / Triploidy / Gynogenesis / European sea bass / Dicentrarchus labrax

\begin{abstract}
Résumé - Nous utilisons la morphométrie géométrique pour caractériser la variation de forme du corps chez des bars gynogènes méiotiques (tous les gènes proviennent de la femelle) et chez des bars triploïdes en comparaison à celle d'individus témoins diploïdes. Les coordonnées de 13 points de repère ont été enregistrés sur les silhouettes d'individus âgés de 34 mois, du groupe témoin $(n=81)$, des individus gynogènes $(n=117)$ et des triploïdes $(n=131)$ d'une même fratrie issue de chacune des deux femelles (A et B). Trois axes principaux de variation morphométrique sont cohérents, et ceux-ci participent à 60,8 et $57,6 \%$ de la variabilité totale chez les femelles A et B, respectivement. Il $\mathrm{y}$ a des déviations significatives de forme chez les poissons triploïdes et chez les gynogènes par rapport aux témoins, et les différences sont particulièrement évidentes chez la progéniture d'une femelle. Dans l'ensemble, les triploïdes présentent une forme plus svelte que les diploïdes, tandis que les poissons gynogènes sont plus hauts de corps et ont un pédoncule caudal plus flexible et des marques sur le crâne. Les résultats sont discutés en particulier en relation avec la caractérisation de poissons triploïdes à des fins commerciales.
\end{abstract}

\section{Introduction}

The global production of European sea bass (Dicentrarchus labrax) increased from 1200 tonnes in 1989 to nearly 103000 tonnes in 2008 (source: Federation of European Aquaculture Producers 2008), the increase being due to the development of reliable larval rearing techniques and efforts devoted to improve juvenile production. Cultured sea bass are commonly marketed at a size (around $450 \mathrm{~g}$, and up to 600-800 g) above that at which there is sexual maturation of male fish (12 years; 50-300 g) and some female fish (3 years; approx. $700 \mathrm{~g}$ ). Precocious sexual maturation and skewed sex-ratios

\footnotetext{
${ }^{\text {a }}$ Corresponding author: Stefano.Peruzzi@uit.no
}

in favour of males under culture conditions represent major drawbacks in commercial production (Zanuy et al. 2001; Felip et al. 2006). Triploidy and gynogenesis may be potential tools for the improvement of somatic growth, carcass quality and for sex-control in this species (reviewed by Felip et al. 2001), and the use of sterile triploids may be a way to avoid genetic interaction between farmed and wild stocks following accidental escapes. In a previous study, we have shown that while triploid sea bass did not show superior growth over diploids they exhibited some qualitative traits that could benefit the aquaculture industry (Peruzzi et al. 2004). On the other hand, information on the morphometric traits of triploid and gynogenetic sea bass is still lacking. 
Differences in the length and shape of fins, and in the head region have been observed between diploids and triploids of several species using traditional morphometric methods (see reviews by Benfey 1999; Tiwary et al. 2004). For example, in the Indian catfish, Heteropneustes fossilis (Bloch), the ratio between standard length and body depth (SL/BD) has proved to be an effective morphometric indicator of triploid status allowing accurate segregation of the two ploidy groups (Tiwary et al. 1999).

Geometric morphometrics (GM) is a powerful tool used to quantify and analyse shape differences (Zelditch et al. 2004). On the basis of a series of morpho-anatomical descriptors or landmarks, shape changes are visualised as deformation grids and the numerical output is analysed with multivariate statistics. GM has become an established method for the evaluation of shape differences in many organisms, including fish, because it can provide higher resolution and visual expression than traditional morphometric approaches. In fish, GM has been used in population studies (Haas and McPhail 2001; Valentin et al. 2002; Ergüden and Turan 2005; Leinonen et al. 2008), analysis of trophic polymorphism (Olsson et al. 2007; Svanbäck and Eklöv 2004) biomass estimation (Hockaday et al. 2000), evaluation of larvae and fry quality (Cataudella et al. 1995; Loy et al. 1995; Verhaegen et al. 2007), and for the assessment of environmental and genetic effects (Loy et al. 1999a,b; Von Cramon-Taubadel et al. 2005; Kouttouki et al. 2006). Loy et al. (2000) indicated that external body morphology of cultured sea bass is an important commercial feature because it can be used as a quality criterion by potential consumers.

The objective of this study was to investigate body shape characteristics of meiotic gynogenetic and triploid sea bass and to compare these with diploid controls as a further step towards the assessment of these fish for commercial and research applications. For this purpose we used a GM approach based on analysis of landmark coordinates to describe and quantify the nature and extent of morpho-anatomical changes in 34month-old communally reared fish that were the offspring of two females.

\section{Materials and methods}

\subsection{Production of fish}

Details of the production, rearing and sampling methods are given in Peruzzi et al. (2004). Briefly, control, meiotic gynogenetic (obtained by suppression of the second meiotic division in eggs) and triploid fish issued from two females (A and B) and one male were reared separately but under the same rearing conditions until the age of 6 months. At this age, fish were marked with visible implant fluorescent elastomer tags (Northwest Marine Technology, Anacortes, Washington, USA), and the fish were then reared communally in duplicated tanks. At 34 months of age, randomly selected fish from each group (weight range: $317-590 \mathrm{~g}$ ) were sacrificed by an overdose of anaesthetic (Eugenol 50 ppm, Freeman-Cooper, San Francisco, USA) and measured. Fish showing vertebral fusions, dorso-ventral (lordosis and kyphosis) flexures or other visible skeletal deformities were omitted from the study. For

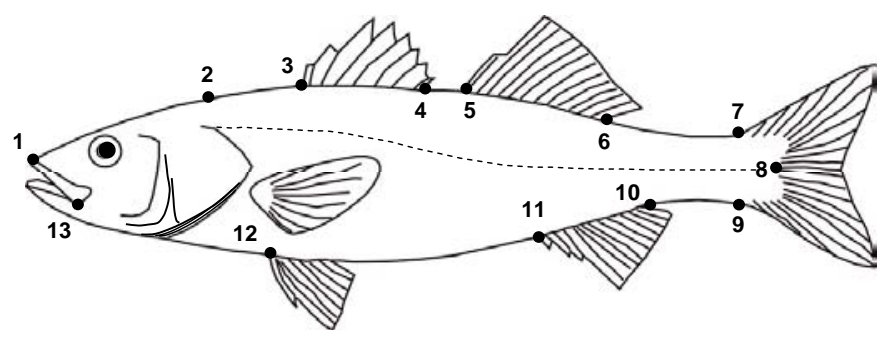

Fig. 1. Location of the morphometric landmarks on sea bass, Dicentrarchus labrax. Landmarks refer to: (1) anterior tip of snout at upper jaw; (2) posterior part of neurocranium (start of scaled nape); (3) origin of first dorsal fin; (4) posterior insertion of first dorsal fin; (5) origin of second dorsal fin; (6) posterior insertion of second dorsal fin; (7) anterior attachment of dorsal membrane from caudal fin; (8) posterior end of vertebrate column; (9) anterior attachment of ventral membrane from caudal fin; (10) posterior insertion of anal fin; (11) origin of anal fin; (12) origin of pelvic fin; (13) most posterior point of maxillary.

this purpose, fish were placed on a plastic tray and examined by soft X-rays (General Electric 500T X-ray generator; voltage $30 \mathrm{kV}$; automatic exposition cell at $60 \mathrm{~mA}$ per $0.03 .0 .05 \mathrm{~s}$ ) as described in Peruzzi et al. (2004).

\subsection{Morphometric measurements and analyses}

Fish were placed on a light polystyrene board on their right side and with a natural body posture; the fins were extended and held in position using dissecting needles. The fish were then photographed using an ION RC-260 Still Video Camera (Canon Inc., Tokyo, Japan), and the images were captured using a computer frame-grabber, initialized and analyzed using the ImageJ software (Version 1.38, National Institutes of Health, Maryland, USA; available at http://rsb.info.nih.gov/ $\mathrm{ij} /$ ). A total of 13 landmarks were chosen and measured (Fig. 1) with a scale bar being used as calibre to translate distances from pixels into millimetres. Landmark coordinates $(x, y)$ were imported into Microsoft Office Excel (Microsoft@, USA) for analysis.

A total of 81 control (A, 31; B, 50), 131 triploid (A, 78; $\mathrm{B}, 53)$, and 117 gynogenetic $(\mathrm{A}, 60 ; \mathrm{B}, 57)$ fish were analyzed. The analyses were performed separately on the offspring of individual females following a multi-step morphometric protocol (Adams et al. 2004). Variation introduced as a result of differences in position, orientation and scale (size correction) was removed using a generalized Procrustes analysis (GPA), and a principal components analysis (PCA) was applied to calculate the main axes of morphometric variation. The Riemannian shape distance rho (i.e. Kendall's rho) was calculated for the whole set of configurations to examine possible correlations between body size (centroid size) and shape. Tests for mean shape differences among control and treated groups were undertaken using Hotelling's $t^{2}$-test and re-sampling procedures for probability calculation (Dryden and Mardia 1998; Amaral et al. 2006). The ordination results were summarized using scatterplots with body shape variations (mean $\pm 1 \mathrm{SD}$ ) sketched along the associated ordination axis. Mean shape deviations among groups were summarized 


\section{Female A}
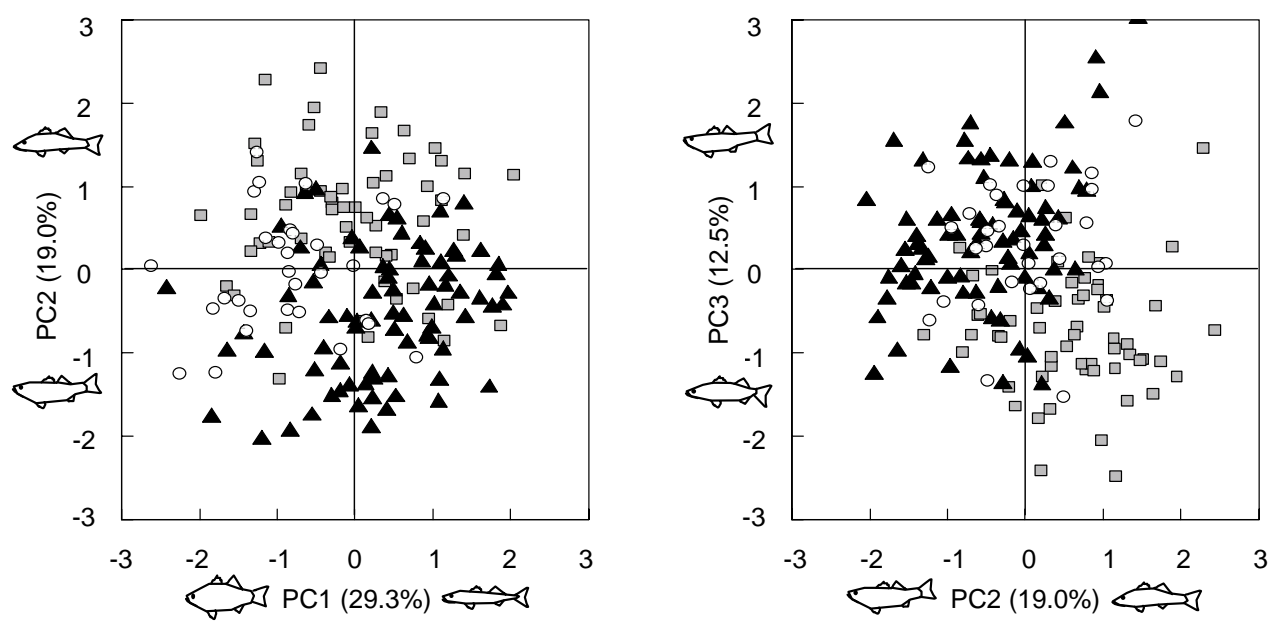

Female B


Fig. 2. Scatterplots of ordination results depicting variation in morphometry within and among control (white circle), gynogenetic (grey square) and triploid (black triangle) groups. Shape variation along the ordination axes is illustrated by the shape configurations at $\pm 1 \mathrm{SD}$ from the mean.

by superimposing shape configurations of control and treatment groups in landmark-based vector plots, and using thin plate spline (TPS) deformation grids. All analyses were performed using the statistical software R, package "shapes" (version 1.0-12, by Ian Dryden; Claude 2008). The critical value $\alpha$ was set at 0.05 .

\section{Results}

No relationships between body size and shape (rho) were observed (female $\mathrm{A}, R^{2}=0.0084$ and $p=0.12$; female $\mathrm{B}$, $R^{2}=0.0068$ and $p=0.15$ ). The main axes of shape variation were consistent between the offspring of female A and $\mathrm{B}$ (Fig. 2). The first ordination axis (PC1), accounting for 29.3 and $27.6 \%$ of the total variation in females $\mathrm{A}$ and $\mathrm{B}$ respectively, can be interpreted as a gradient of body depth (dorsoventral expansion). The second axis (PC2), accounting for 19.0 and $19.7 \%$ of the total variation in females $\mathrm{A}$ and $\mathrm{B}$ respectively, captures the degree of body curvature (body flexion or dorso-ventral curving). Finally, the third axis (PC3), accounting for 12.5 and $10.3 \%$ of the total variation in females $\mathrm{A}$ and $\mathrm{B}$ respectively, expresses a change in shape of the caudal peduncle (tail region). Overall, gynogenetic fish had deeper, less concave bodies than triploids, whereas the controls were intermediate (Fig. 2, left panels). The caudal peduncle region in the triploid fish was elongated whereas in the gynogenetic fish it was shorter. Correlations between body size and shape variables were small and not significant. Body shape differences highlighted by the vector plots and thin plate spline diagrams are shown in Figures 3 and 4, respectively. The triploid and gynogenetic fish differed from their respective controls, but this was particularly evident for the offspring of female A. Relative to the control group, the triploid fish showed a general body shearing captured by PC1 (female A, $H=7.06$ and $p=0.005$; female $\mathrm{B}, H=2.91$ and $p=0.005$ ), whereas the gynogenetic fish displayed shear driven by a downward slide of the cranial and post-cranial landmarks, accompanied by an upward flexion of the peduncular landmarks captured by the remaining two ordination axes (female $\mathrm{A}, H=5.50$ and $p=0.005$; female $\mathrm{B}, H=18.71$ and $p=0.005$ ). 


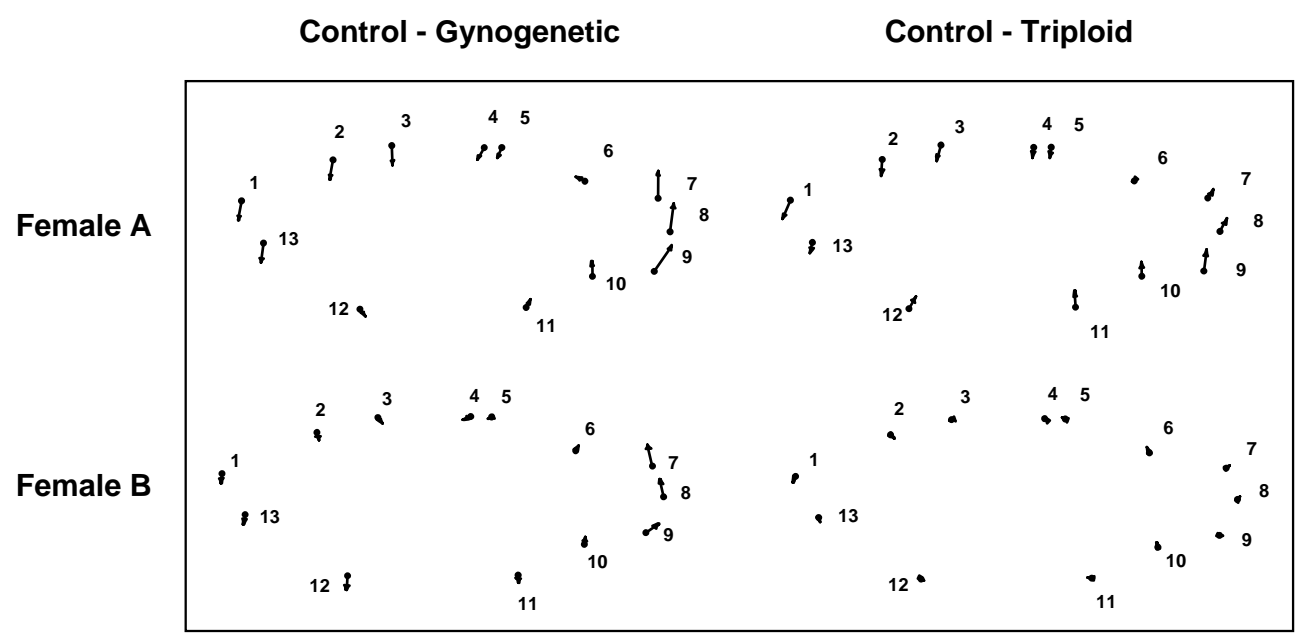

Fig. 3. Landmark-based vector plots depicting magnitude and direction of mean shape deviations between control and treatment groups in female A and B.

Control

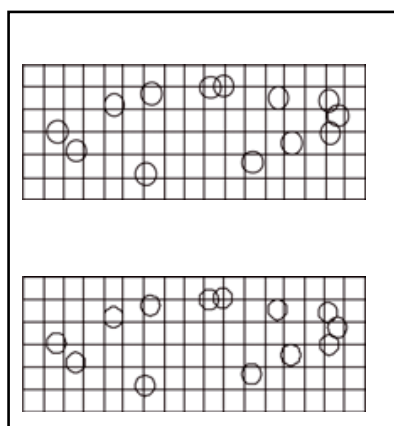

Gynogenetic


Triploid

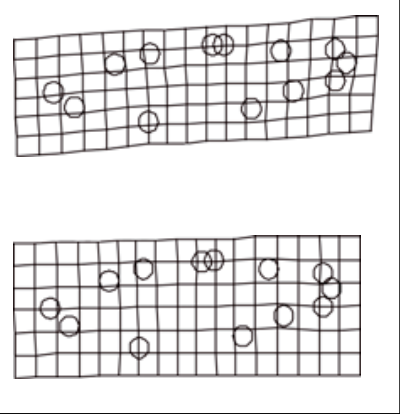

Fig. 4. Thin-plate spline (TPS) deformation grids illustrating changes in mean shape in gynogenetic and triploid fish (female A and B) as stretching, compression or shearing of the entire landmark configuration relatively to control group.

\section{Discussion}

In this work, triploid sea bass had on average a more slender body shape than the diploids and this was accompanied by a lengthening of the peduncular region, whereas the gynogenetic fish were deeper bodied, and had bent caudal peduncles and cranial features. Overall, the body shape differences were not correlated with size and were more pronounced in the offspring of female $\mathrm{A}$ than female $\mathrm{B}$, indicating a possible parental effect on such morphological features. The general body shearing of triploids revealed in the present study is in accord with previous measurements made on the same experimental group (Peruzzi et al. 2004) in which the condition factor $\left(\mathrm{K}=\right.$ Body Weight/Body Length $\left.{ }^{3} \times 100\right)$ was approximately $12 \%$ lower in triploid fish than in diploid siblings. A maternal effect was also noted by Peruzzi et al. (2004).

Morpho-anatomical differences between diploids and triploids have been reported in carp (Cyprinus carpio), grass carp (Ctenopharyngodon idella), bighead carp (Aristichthys nobilis), tench (Tinca tinca) and Indian catfish (Heteropneustes fossilis) as reviewed by Tiwary et al. (2004). Lower jaw deformities have been described as the most common abnormal features in triploid Atlantic salmon although it is unclear whether these are directly associated to ploidy, or are the result of rapid growth of the fish in seawater (Benfey 1999). In general, it remains uncertain if body shape differences and abnormalities observed in triploid fish are a direct consequence of the treatments used to produce them or are a reflection of the triploid condition per se. In this study, we analyzed triploid and gynogenetic siblings generated using the same pressure treatment conditions shortly after egg fertilisation with either normal or UV-irradiated sperm. A group that did not undergo any pressure shock treatment was reared as the control. We have demonstrated that body shape differences from the control occur in both triploid and gynogenetic siblings. Importantly, the differences occur around different morphometric axes in the triploid and gynogenetic fish suggesting that ploidy status (genetic composition) rather than pressure treatment per se may be the underlying causative factor for the observed differences.

A rounding of the head, a prominent ventral profile and a characteristic bending of the caudal region have been shown to be associated with lordosis in cultured sea bream (Loy et al. 1999a) and sea bass (Loy et al. 2000). Sfakianakis et al. (2006) analyzed the effects of this deformity on the body shape of juvenile sea bass and demonstrated that the changes were most noticeable in the posterior abdominal region and could be 
quantified by specific body landmarks (dorsal, pelvic, caudal and anal fins). In the present study, fish that showed signs of lordosis were excluded from the analyses (see materials and methods) tending to indicate that the altered body features reported here may not be linked to the presence of major skeletal anomalies or deformities. Furthermore, detailed analyses performed on the same experimental groups at the age of 6 months (Peruzzi et al. 2004) showed no differences in the percentage of vertebral column deformities (mean 6\%).

In addition to giving the possibility of enhanced growth, the use of sterile triploids in aquaculture has been suggested as means to protect the genetic diversity of native populations by reducing the risk of interbreeding with escapees. Nevertheless, before production of triploid sea bass is set into motion, their commercial value must be fully evaluated. We have previously shown that triploid sea bass possess potentially valuable qualitative traits, but their growth performance is lower than that of diploids until the age of 4 years (Peruzzi et al. 2004). More recently it has been shown that triploid females might reach a larger size than triploid males and their diploid counterparts but at older age only (Felip et al. 2009). Another desirable characteristic that might be of interest to producers and consumers is body shape. In this study, we show that triploid fish display a slim, streamlined body figure common of wild captured sea bass that could be used as a quality criterion by consumers increasing the acceptance and market value of the farmed product (Chatain pers. comm.). Additional studies will be required to determine the degree of parental influence over such morphological features in a large number of individuals as a further step towards the assessment of these fish for aquaculture purposes.

Acknowledgements. We are grateful to Jérôme Bugeon (INRA/SCRIBE, France), Fride Tonning, Ronald Berntsen and Richard Buvang (Department of Arctic and Marine Biology, University of Troms $\varnothing$ ) for their valuable assistance during data acquisition. We offer special thanks to Prof. Malcolm Jobling for his revision of the document. The authors wish to acknowledge the anonymous referees for their helpful comments on the paper. The project was partly supported by OFIMER (Office National Interprofessionnel des Produits de la Mer et de l'Aquaculture) under contract OFIMER/IFREMER $\mathrm{N}^{\circ}$ 020/01/C.

\section{References}

Adams D.C., Rohlf F.J., Slice D.E., 2004, Geometric morphometrics: ten years of progress following the "revolution". Ital. J. Zool. 71, $5-16$.

Amaral G.J.A., Dryden I.L. Wood A.T.A., 2006, Pivotal bootstrap methods for k-sample problems in directional statistics and shape analysis. J. Am. Stat. Assoc. 102, 695-707.

Aquamedia, 2008, http://www.aquamedia.org.

Benfey T.J., 1999, The physiology and behaviour of triploid fishes. Rev. Fish. Sci. 7, 39-67.

Cataudella S., Marino G., Ferreri F., dell'Aquila M., Loy A., Scardi M., Boglione C., 1995, Morphology and morphometrics to evaluate finfish larval and fry quality: the case of the sea bass
Dicentrarchus labrax. In: Lavens, P., Jaspers, E., Roelants, J. (Eds.), Larvi '95 Fish and Shellfish Larviculture Symposium, EAS Spec. Publ. No. 24, pp. 60-63.

Claude J., 2008, Morphometrics with R. Springer, New York

Dryden I.L., Mardia K.V., 1998, Statistical shape analysis. John Wiley Publishers, Chichester.

Ergüden D., Turan C., 2005, Examination of genetic and morphologic structure of sea-bass (Dicentrarchus labrax L., 1758) populations in Turkish coastal waters. Turk. J. Vet. Anim. Sci. 29, 727-733.

Felip A., Zanuy S., Carrillo M., Piferrer F., 2001, Induction of triploidy and gynogenesis in teleost fish with emphasis on marine species. Genetica 111, 175-195.

Felip A., Zanuy S., Carrillo M., 2006, Comparative analysis of growth performance and sperm motility between precocious and nonprecocious males in the European sea bass (Dicentrarchus labrax L.). Aquaculture 256, 570-578.

Felip A., Carrillo M., Zanuy S., 2009, Older triploid fish retain impaired reproductive endocrinology in the European sea bass Dicentrarchus labrax. J. Fish Biol. 75, 2657-2669.

Haas G.R., McPhail J.D., 2001, The post-Wisconsinan glacial biogeography of bull trout (Salvelinus confluentus): a multivariate morphometric approach for conservation biology and management. Can. J. Fish. Aquat. Sci. 58, 2189-2203.

Hockaday S., Beddow T.A., Stone M., Hancock P., Ross L.G., 2000, Using truss networks to estimate the biomass of Oreochromis niloticus, and to investigate shape characteristics. J. Fish Biol. 57, 981-1000.

Kouttouki S., Georgakopoulou E., Kaspiris P., Divanach P., Koumoundouros G., 2006, Shape ontogeny and variation in the sharpsnout seabream, Diplodus puntazzo (Cetti 1777). Aquac. Res. 37, 655-663.

Leinonen T., Cano J.M., Mäkinen H., Merilä J., 2008, Contrasting patterns of body shape and neutral genetic divergence in marine and lake populations of threespine sticklebacks. J. Evolution. Biol. 19, 1803-1812.

Loy A., Boglione C., Zanello L., Ferrucci L., Cataudella S., 1995, Morphometrics and image analysis as an emerging method to evaluate sea bass larval quality. In: Lavens P., Jaspers E., Roelants J. (Eds.) Larvi '95 Fish and Shellfish Larviculture Symposium, EAS Spec. Publ. No. 24, 373-376.

Loy A., Boglione C., Cataudella S., 1999a, Geometric morphometrics and morpho-anatomy: a combined tool in the study of sea bream (Sparus aurata, Sparidae) shape. J. Appl. Ichthyol. 15, 104-110.

Loy A., Bronzi P., Molteni S., 1999b, Geometric morphometrics in the characterisation of the cranial growth pattern of Adriatic sturgeon Acipenser naccarii. J. Appl. Ichthyol. 15, 50-53.

Loy A., Boglione C., Gagliardi F., Ferrucci L., Cataudella S., 2000, Geometric morphometrics and internal anatomy in sea bass shape analysis (Dicentrarchus labrax L., Moronidae). Aquaculture 186, 33-44.

Olsson J., Svanbäck R., Eklöv P., 2007, Effects of resource level and habitat type on behavioral and morphological plasticity in Eurasian perch. Oecologia 152, 48-56.

Peruzzi S. Chatain B., Saillant E., Haffray P., Menu B., Falguière J-C., 2004, Production of meiotic gynogenetic and triploid sea bass, Dicentrarchus labrax L.: 1. Performances, maturation and carcass quality. Aquaculture 230, 41-64. 
Sfakianakis D.G., Georgakopoulou E., Kentouri M., Koumoundouros G., 2006, Geometric quantification of lordosis effects on body shape in European sea bass, Dicentrarchus labrax (Linnaeus, 1758). Aquaculture 256, 27-33.

Svanbäck R., Eklöv, P., 2004, Morphology in perch affects habitat specific feeding efficiency. Funct. Ecol. 18, 503-510.

Tiwary B.K., Kirubagaran R., Ray A.K., 1999, Altered body shape as a morphometric indicator of triploidy in Indian catfish Heteropneustes fossilis (Bloch). Aquac. Res. 30, 907-910.

Tiwary B.K., Kirubagaran R., Ray A.K., 2004, The biology of triploid fish. Rev. Fish Biol. Fish. 14, 391-402.

Valentin A., Sévigny J.-M., Chanut J.-P., 2002, Geometric morphometrics reveals body shape differences between sympatric redfish Sebastes mentella, S. fasciatus and their hybrids in the Gulf of St. Lawrence. J. Fish Biol. 60, 857-875.
Verhaegen Y., Adriaens D., De Wolf T., Dhert P., Sorgeloos P., 2007, Deformities in larval gilthead sea bream (Sparus aurata): A qualitative and quantitative analysis using geometric morphometrics. Aquaculture 268, 156-168.

Von Cramon-Taubadel N., Ling E.N., Cotter D., Wilkins N.P., 2005, Determination of body shape variation in Irish hatchery-reared and wild Atlantic salmon. J. Fish Biol. 66, 1471-1482.

Zanuy S., Carrillo M., Felip A., Rodríguez L., Blázquez M., Ramos J., Piferrer F., 2001, Genetic, hormonal and environmental approaches for the control of reproduction in the European sea bass (Dicentrarchus labrax L.). Aquaculture 202, 187-203.

Zelditch M.L., Swiderski D.L., Sheets H.D., Fink W.L., 2004, Geometric Morphometrics for Biologists: A Primer. Elsevier Academic Press, New York and London. 